\title{
Antecedents of Overall E-service Quality and Brand Attachment in the Banking Industry
}

\author{
Gul-e-Rana $\mathbb{D}^{* 1}$, Dr. Noor Azizah Mohamadali ${ }^{2}$ \\ ${ }^{1}$ Kulliyyah of Information and Communication Technology, International Islamic \\ University Malaysia (IIUM), Malaysia and Department of Management Sciences, Yanbu \\ University College, Yanbu, Saudi Arabia \\ ${ }^{2}$ Kulliyyah of Information and Communication Technology, International Islamic \\ University Malaysia (IIUM), Malaysia
}

* Corresponding author: guleranna@gmail.com

\section{Article History \\ Received 2020-09-02 \\ Revised 2020-10-15 \\ Accepted 2020-10-16 \\ Published 2020-10-27 \\ Keywords \\ Brand Attachment \\ Website Design \\ E-fulfillment \\ Overall e-service quality}

How to cite?

Gul-e-Rana, \& Mohamadali, N. A. (2020). Antecedents of Overall E-service Quality and Brand Attachment in the Banking Industry. SEISENSE Journal of Management, 3(6), 26-34. doi:

$10.33215 /$ sjom.v3i6.451

\begin{abstract}
Purpose - The study aims to examine the impact of website design, e-fulfillment, e-service and e-security on overall e-service quality and its impact on brand attachment.

Design/methodology/approach - Data of 425 respondents was collected from the internet banking industry users through an online survey. Further, PLS-SEM was employed to analyze the data.

Findings - Results indicate that the impact of e-security, ecustomer service, and e-fulfillment on overall e-customer service quality was supported. In contrast, the impact of website design was not supported. Further, overall, e-service quality also has a significant impact on brand attachment.

Originality/value - This study suggested and tested a brand attachment framework for the banking industry to support strategy formulation for managers.
\end{abstract}




\section{Introduction}

Brand attachment captures emotional and cognitive bonding and represents the connection of brand and self (Park, MacInnis, \& Priester, 2006). Park, MacInnis, Priester, Eisingerich, and Iacobucci (2010) argued that brand and self-connection are recognized by the extent of easiness they bring in customers' minds. Likewise, the brand is a distinctive personality, and customers develop a relationship with the brand in the same way as they do with people even though brands have different attributes (Chowdhury, Chun, Choi, \& Friend, 2020; Thach \& Olsen, 2006). Hence, brand attachment refers to a strong bond between individuals and brands (Park et al., 2010). Organizations are providing online services structure users' minds to save their time by learning e-services. Eservice quality is assessed based on the time of users it saves and fewer hassles it offers, and according to Thach and Olsen (2006), such type of services may cause customers to attach to the brand. Customers can develop a forging relation of a companion with a brand (Dennis, Papagiannidis, Alamanos, \& Bourlakis, 2016; Wu, Cai, \& He, 2019). Rana, Azizah, Ali, Shah, And Muhammad (2018) also argued that overall e-service quality might enhance a customer's attachment towards a brand providing such services. However, overall, e-service quality can support brand attachment and need to be answered (Blut, Chowdhry, Mittal, \& Brock, 2015; Rana et al., 2018).

The concept of service quality remained popular for almost from the previous two decades. Recent technological developments propel this concept to e-commerce, mainly due to the emergence of internet marketing. Researchers are almost agreed that the concept of e-service quality is different from service quality in an offline setting. Since in e-commerce, service quality refers to virtual markets in online settings. Hence, what leads to overall e-service quality in the banking industry is still being debated. This current study is keen to address these questions above, drawing on brand attachment theory.

Based on attachment theory (Bowlby, 1979), this study tends to have theoretical and practical contributions. One current study considers the impact of overall e-service quality on brand attachment in the banking industry, which was yet to be considered (Rana et al., 2018). Two, though the researchers have considered the impact of different constructs on overall e-service quality, the individual effect of e-fulfillment, website design, e-customer service, and security is yet to be considered. This study will empirically test and evaluate the individual influence of each construct on overall e-service quality. Finally, this study also made efforts to have contributions for managers and research students. This study will argue the factors propelling overall e-service quality and its subsequent effect on brand attachment for managers. Hence, managers can adjust their branding strategies. For research students, the concept of branding in the banking industry will further ignite the research. Next, brand attachment theory, literature review, and hypothesis development is discussed, followed by methodology and results. Finally, discussions are made.

\section{Brand Attachment Theory}

Brand attachment theory (Bowlby, 1979) suggests that the scenes, impressions, and experiences are essential to shaping attachment. Based on brand attachment theory, this study, e-fulfillment, website design, e-customer service, and security, is considered scenes and impressions, overall e-service quality as experience while brand attachment as an attachment. Brand attachment theory (Bowlby, 1979) is essential to consider these linkages, particularly in the online banking industry context. Next, details on the literature review and hypothesis development are discussed. 


\section{Literature Review and Hypothesis Development}

\section{Overall e-service quality and brand attachment}

Brand attachment refers to a state of mind to feel a strong connection with a brand. Accordingly, Phillips and Baumgartner (2002) argued that attachment results from long-term relationships between customers and those who provide services. The service firm achieves it via reasonable marketing efforts. E-service quality is referred to as customers assessing e-service quality in virtual market service (Van Riel, Liljander, \& Jurriens, 2001). Whether overall e-service quality impacts brand attachment is yet to be answered (Blut et al., 2015). An individual can emotionally attach to a particular object based on the interaction between the object and the particular individual (Thomson, MacInnis, \& Park, 2005). While attachment theory considers and concentrates more on interactions (Bowlby, 1979), these interactions can be in online settings. Customers attribute human characteristics to different brands and may have relation with brands in the same way as they do with humans (Aaker, 1997; Fournier, 1998). A shortage of research has examined the impact of overall service quality on the banking industry's brand attachment. Hence, based on attachment theory (Bowlby, 1979) and aforementioned arguments, the following relationship is hypothesized;

H1: E-service quality will positively influence brand attachment.

\section{Website design and overall e-service quality}

According to Riaz, Gregor, and Lin (2018), website design is a joint function of a website that facilitates online users' experience in offline settings. In addition to this, it is shaping cyberspace following physical space. In the banking industry, websites are an essential source of online information. Websites provide various information (Manika, Gregory-Smith, \& Papagiannidis, 2018) on bank offerings, particularly about account opening procedures, deposit rates, credit cards, personal finance, auto finance, and home financing. A good website is a source of positive impressions and opinions. It is well established in the literature that a well-designed website can improve customers' perceptions about a service firm (Foroudi et al., 2018). Hence, the banking industry is the one that directly can be affected, where the website became intermediary between a customer and the bank for disseminating information regarding balance, account statement, and enabling customers to do transactions. Hence, in the banking industry, it can be argued that the better the perception of website design better be the perception of overall e-service quality and the following relationship is hypothesized;

H2: Website design and overall e-service quality are positively related to each other.

\section{Fulfillment and overall e-service quality}

Fulfillment is considered an organization's ability to ensure that customers received the same what they think they asked for (Blut, 2016). Fulfillment refers to an organization's ability to provide promised service perfectly (Stank et al., 1999, 2003). In the financial service sector, banks encourage their customers to use online sites (Al-Hawari and Ward, 2006). Customers notice about value and convenience they are given by their banks (Lewis and Soureli, 2006). Thus, it can be assumed in the banking industry that customer fulfillment can be related to overall e-service quality. Hence, this can be hypothesized as;

H3: Fulfillment will have a positive relationship with overall e-service quality.

\section{E-service and overall e-service quality}

According to Zeithaml, Bitner, and Gremler (2006), e-customer service is a service that can be delivered through the internet. Accordingly concept of e-customer service has developed, and now organizations have realized the importance of satisfying their customers by providing better services online (Bottani \& Rizzi, 2006). Thus, considering customer service's importance due to their organizational profitability contribution, organizations 
consider it an important part to excel in the market. The banking sector is developing continuously due to immense competition, discerning customers, globalization, and improved services (Ramseook-Munhurrun \& Naidoo, 2011). To become more effective, competitive, and flexible, banks realize the importance of internet usage benefits to satisfy their modern customers. Thus, it can be argued that better customer services may be positively related to overall e-service quality. Furthermore, better customer service is considered to contribute more to overall e-service quality. Based on these arguments, we may propose that:

\section{H4: Customer service will positively influence overall e-service quality}

\section{Security and overall e-service quality}

Security is a customer's concern about the privacy and security of their online banking transactions. Customers are concerned about their personal information and are also conscious of financial loss when they pay through their credit cards (Blut, 2016; Bressolles et al., 2014). Customers also expect organizations to protect their customers from junk emails, theft, and fraudulent activities. Customers can avoid online services due to banks' online security risks (Qayyum, Rehman, Saleemi, Ilyas, \& Rafiq, 2018). Based on these arguments, this study considers the effect of e-security on overall e-service quality and hypothesized that;

H5: Security will have a positive impact on overall e-service quality

\section{Methodology}

The data was collected from the banking customers who used online banking services in an Asian banking industry context, Pakistan, by using an online survey. To decide on sample size Gpower calculator was used. The maximum number of arrows pointing to a construct was 4; the effect size was considered as 0.05 , and the power required was 0.90 ; the required sample size was 313. This study was set out more than the minimum required sample size.

The scales of the constructs were adopted from the previous literature. Website design (5 items), fulfillment (3 items), e-customer service ( 3 items), and security ( 3 items) were borrowed from Wolfinbarger and Gilly (2003). Overall e-service quality scale was borrowed from Carlson and O'Cass (2011) with three items, while brand attachment with eight items was adopted from Chiou, Chi-Fen Hsu, and Hsieh (2013). After conducting the pilot test, the primary data was collected. At the design stage, it was ensured that once the customers respond to all the required items, they can proceed with the response submission. Hence, there was no missing value in the data.

\section{Results}

This study compromised on data of a total of four hundred and twenty-five respondents. Out of these respondent's 30.4 percent were female, and 69.6 were male. Only 6.6 percent of the respondents were using the internet for less than one hour, while 32.5 percent were using 1-3 hours, 28.5 percent were using 3-5, 15.8 percent were suing 5-7 hours, and 16.2 percent were using the internet above 7 hours. Further, to evaluate the results, partial least structural equation modeling is used by employing SmartPLS3. This approach considers the measurement model first, and on a satisfactory measurement model, hypotheses are evaluated (Muhammad, 2019). Accordingly, the measurement model was evaluated first.

\section{Measurement Model}

Reliability and validity were considered in the measurement model (Hair, Hult, Ringle, \& Sarstedt, 2016; Muhammad, 2019). To test the measurement model PLS algorithm was run. Items BrA3, BraA4, OSQ1 were deleted due to high cross-loadings, and the model was reassessed. For reliability, Cronbach alpha $(\mathrm{CrA})$ and composite reliability (CR) were assessed. The values of $\mathrm{CrA}$ and $\mathrm{CR}$ were more significant than 
the minimum threshold of 0.7. Hence, having satisfactory reliability (Hair et al., 2016; Muhammad \& GulE-Rana, 2020).

For convergent validity, loadings, and average variance extracted (AVE) were considered. Table 1 shows the loadings and AVE values greater than 0.707 and 0.50 , respectively, to confer a good convergent validity (Hair et al., 2016).

Table 1: Reliability and convergent validity

\begin{tabular}{|c|c|c|c|c|}
\hline Items & Loadings & $\mathrm{CrA}$ & $\mathrm{CR}$ & AVE \\
\hline BrA1 & 0.796 & 0.921 & 0.938 & 0.716 \\
\hline $\mathrm{BrA} 2$ & 0.861 & & & \\
\hline $\mathrm{BrA} 5$ & 0.838 & & & \\
\hline BrA6 & 0.850 & & & \\
\hline $\mathrm{BrA} 7$ & 0.871 & & & \\
\hline $\mathrm{BrA} 8$ & 0.860 & & & \\
\hline ESer1 & 0.832 & 0.825 & 0.896 & 0.741 \\
\hline ESer2 & 0.864 & & & \\
\hline ESer3 & 0.886 & & & \\
\hline OSQ2 & 0.948 & 0.880 & 0.943 & 0.893 \\
\hline OSQ3 & 0.942 & & & \\
\hline EFul1 & 0.820 & 0.811 & 0.888 & 0.725 \\
\hline EFul2 & 0.868 & & & \\
\hline EFul3 & 0.866 & & & \\
\hline ESec1 & 0.912 & 0.895 & 0.935 & 0.827 \\
\hline ESec2 & 0.921 & & & \\
\hline ESec3 & 0.895 & & & \\
\hline WeD1 & 0.831 & 0.868 & 0.904 & 0.654 \\
\hline WeD2 & 0.811 & & & \\
\hline WeD3 & 0.827 & & & \\
\hline WeD4 & 0.734 & & & \\
\hline WeD5 & 0.838 & & & \\
\hline
\end{tabular}

Heterotrait-Monotrait Ratio (HTMT) was suggested by Henseler, Ringle, and Sarstedt (2015) to evaluate discriminant validity. HTMT values should be 0.90 or less for discriminant validity. The results in Table 2 indicate that HTMT values were less than 0.90 to have a satisfactory discriminant validity, as shown in Table 2. Once the measurement model was found satisfactory for reliability and validity, then the structural model was assessed.

Table 2: Heterotrait-Monotrait Ratio (HTMT)

\begin{tabular}{lrrrrrr}
\hline & EFul & ESec & ESer & OSQ & WeD \\
\hline BrA & & & & & & \\
EFul & 0.589 & & & & & \\
ESec & 0.485 & 0.800 & & & & \\
ESer & 0.690 & 0.812 & 0.691 & & & \\
OSQ & 0.695 & 0.820 & 0.693 & 0.788 & \\
WeD & 0.581 & 0.889 & 0.794 & 0.755 & 0.719 \\
\hline
\end{tabular}




\section{Structural Model}

To evaluate the structural model, t-statistics, effect size, and variance explained, $\mathrm{R}^{2}$ and $\mathrm{Q}^{2}$ were evaluated (Muhammad, Mahadi, \& Hussin, 2017). To evaluate t-values, a bootstrapping procedure with 5000 subsamples was run as suggested by (Hair et al., 2016; Muhammad \& Gul-E-Rana, 2020). The results indicated in Table 3, show that $\mathrm{H} 1$ ( $\beta=0.626, \mathrm{p}<0.000), \mathrm{H} 3(\beta=0.320, \mathrm{p}=0.000), \mathrm{H} 4(\beta=0.315, \mathrm{p}=0.000)$ and $\mathrm{H} 5(\beta=0.149$, $\mathrm{p}=0.023)$ were supported, while $\mathrm{H} 2(\beta=0.068, \mathrm{p}=0.189)$ was rejected. The effect sizes $\mathrm{f}^{2}$ were ranging from 0.023 to 0.645 . Effect $\mathrm{f}^{2} 0.02$ is considered small, 0.15 as a medium, and 0.35 as large (Cohen, 1992). Hence, the effect sizes of exogenous constructs on endogenous constructs in the proposed model ranged from small to large. Overall, e-service quality (OSQ) explained 39.2 percent in the brand attachment (BrA). While, Website design (WeD), e-fulfillment (EFul), e-service (ESer), and e-security (Eser) collectively explained 58.3 percent of variance in OSQ. In addition to this $\mathrm{Q}^{2}$ values for predictive relevance were greater than zero. These values were obtained by using a blindfolding approach in SmartPLS3. In sum, all hypotheses were accepted, except $\mathrm{H} 2$, as shown in Table 3.

Table 3: Hypothesis results

\begin{tabular}{|c|c|c|c|c|c|c|c|c|c|}
\hline Нyp & Paths & $\beta$ & Std. Error & t-values & p-values & $\mathrm{f}^{2}$ & $\mathrm{R}^{2}$ & $\mathrm{Q}^{2}$ & Decision \\
\hline $\mathrm{H} 1$ & OSQ -> BrA & 0.626 & 0.046 & 13.729 & 0.000 & 0.645 & 0.392 & 0.261 & Accepted \\
\hline $\mathrm{H} 2$ & WeD -> OSQ & 0.089 & 0.068 & 1.315 & 0.189 & 0.007 & & & Rejected \\
\hline H3 & EFul -> OSQ & 0.320 & 0.066 & 4.879 & 0.000 & 0.089 & 0.583 & 0.490 & Accepted \\
\hline H4 & ESer $->$ OSQ & 0.315 & 0.058 & 5.408 & 0.000 & 0.118 & & & Accepted \\
\hline $\mathrm{H} 5$ & ESec $->$ OSQ & 0.149 & 0.060 & 2.484 & 0.013 & 0.023 & & & Accepted \\
\hline
\end{tabular}

\section{Discussion}

The study aimed to examine the impact of website design, e-fulfillment, e-customer service, and e-security on overall e-service quality and overall e-service quality on brand attachment in the banking industry was yet to be considered. The impact of overall e-service quality on brand attachment was supported (H1). This result can be explained in the light of brand attachment theory (Bowlby, 1979), which states that the extent to which an individual is emotionally attached to a particular object envisages the interaction with that object (Thomson et al., 2005). Furthermore, attachment theory focuses on human interactions, but literature also shows this relation between humans and brands they use (Aaker, 1997; Fournier, 1998). Hence, this might be why the impact of overall e-service quality on brand attachment was supported. The impact website design overall e-service quality was not supported (H2). This finding is consistent with the argument of Dedeke (2016). Dedeke (2016) argued that e-retailers need to overemphasize the website design's e-service quality as perceived by consumers. Since information task fit affects perceived quality more than web design quality, another reason might be the website with pertinent information, leaving a good impression on consumers compared to the website with less appropriate information despite good design.

The impact of e-fulfillment on overall e-service quality was supported (H3). Recent advancements in technology have changed the service delivery options, specifically in service industries (Dennis, Merrilees, Herington, \& Weaven, 2009). Hence customer's perceptions about overall e-service quality are dependent on these exchanges between customers and banks (Jabnoun \& Hassan Al-Tamimi, 2003). Hence, the value and convenience they receive from their banks are noticed by them (Lewis \& Soureli, 2006), which may be considered a source for evaluating the overall e-service quality. Hence, this might be the reason that the impact of e-fulfillment was supported on overall e-service quality.

The impact of e-customer service on overall e-service quality was also supported (H4). The banking sector is having immense competition and is increasing better services and effectiveness in processes. Hence, to become 
more effective, flexible, and competitive, banks have now realized the importance of the internet to provide customer service better. This discussion concludes that banks should focus on providing better customer services to develop their positive perceptions about overall e-service quality. As researchers also emphasized, the banking sector needs to develop strategies that enhance the overall e-service quality of banks (e.g., Goyal \& Chanda, 2017). Finding in this study is also consistent with this argument and the impact of e- customer service found to influence overall e-service quality positively.

Finally, the impact of e-security on overall e-service quality was also supported (H5). Online security requires system configuration and third-party endorsement by representing signs and logos known to customers to protect their online transactions. In addition to this, Lee and Turban (2001) also claimed that customers need to check how organizations will protect their personal information and their financial details. Moreover, ChienTa Ho and Oh (2009) also argued that e-security seals could shape the customer's trust in websites in an entirely different way. Such studies emphasize getting security assurance by customers during their online transactions because customers can't see the trustworthiness standards visibility. Hence, if companies want to use security seals, they should follow the standards established by third parties to reduce the customers' fear of security. In Pakistani banking, the banking industry's regularity authority assures the customers of banking industry customers to protect financial aspects. This might be the reason that the impact of e-security is supported. Such findings have contributions to theory and practice.

\section{Theoretical Contributions}

Brand attachment is an important but unexplored area that needs to be considered by researchers, particularly in online settings (Blut et al., 2015). Further, the parameters that increase overall e-service quality in banks were yet to be considered (Goyal \& Chanda, 2017). Therefore, this study contributes to the literature by shedding light on this unexplored area and has considered the impact of overall e-service quality on brand attachment and website design, e-fulfillment, e-service and e-security on overall e-service quality. Findings of this study open new avenues to researchers for better understanding the antecedents of overall e -service quality and thereof impact overall e-service quality on brand attachment in banking industry.

\section{Managerial Contributions}

In the banking industry context, this study is important to explore those factors that may influence customers' overall e-service quality and enhance brand attachment to help manager for strategy formulation. This study's results would help policymakers and practitioners of the banking industry understand all significant dimensions of overall e-service quality. Managers can enhance customers' perceptions of overall e-service quality by improving customer service, ensuring secure transactions and e-customer services, and fulfilling their requests on time. Additionally, in service sectors, customers want to have order fulfillment on time. This study suggests that banks should ensure their systems' technical maintenance efficiency to create a better image of order fulfillment and security as a reliable banking firm. Banks need to maintain consistency in providing better services to maintain and enhance their customers' brand attachment and provide unique services is the best way to position the customer's minds and build a strong image of their brand.

\section{Limitations of the study}

This study also has some limitations. The majority of the study respondents were using the internet for more than one hour per day. Hence, the finding should be interpreted accordingly, and banks need to have different strategies to attract those customers for brand attachment who are not using the internet. Further, the study aimed to consider antecedents and outcomes. Accordingly, the mediating role of overall e-service quality was not considered. Future research may consider how e-fulfillment, website design, e-customer service, and security affect brand attachment via overall e-service quality by considering overall e-service quality as a mediator. 
Further, in developing countries, such customers are in a reasonable number. Such a future study might be necessary for attracting customers for brand attachments who are not internet users. This study considered the banking industry. It would be interesting to test the current research framework in different industries and cultures to validate or contradict the results. Future research may consider the influence of overall e-service quality on willingness to pay and behavioral loyalty in the banking industry. In sum, this reasonable effort to fill the gaps in the literature about overall e-service quality and brand attachment in the banking industry.

Funding: This research received no external funding.

Conflicts of Interest: The authors declare no conflict of interest.

\section{References}

Aaker, J. L. (1997). Dimensions of brand personality. Journal of marketing research, 34(3), 347-356.

Blut, M., Chowdhry, N., Mittal, V., \& Brock, C. (2015). E-service quality: A meta-analytic review. Journal of retailing, 91(4), 679-700.

Bottani, E., \& Rizzi, A. (2006). Strategic management of logistics service: A fuzzy QFD approach. International journal of production economics, 103(2), 585-599.

Bowlby, J. (1979). On knowing what you are not supposed to know and feeling what you are not supposed to feel. The Canadian Journal of Psychiatry, 24(5), 403-408.

Carlson, J., \& O'Cass, A. (2011). Developing a framework for understanding e-service quality, its antecedents, consequences, and mediators. Managing Service Quality: An International Journal, 21(3), 264-286. doi:10.1108/09604521111127965

Chien-Ta Ho, B., \& Oh, K.-B. (2009). An empirical study of the use of e-security seals in e-commerce. Online Information Review, 33(4), 655-671.

Chiou, J.-S., Chi-Fen Hsu, A., \& Hsieh, C.-H. (2013). How negative online information affects consumers' brand evaluation. Online Information Review, 37(6), 910-926. doi:10.1108/oir-02-2012-0014

Chowdhury, R., Chun, W., Choi, S., \& Friend, K. (2020). Brand and firm values in distinct national cultures. Asia Pacific Journal of Marketing and Logistics.

Cohen, J. (1992). A power primer. Psychological bulletin, 112(1), 155.

Dedeke, A. N. (2016). Travel website design: Information task-fit, service quality and purchase intention. Tourism Management, 54, 541-554.

Dennis, C., Merrilees, B., Herington, C., \& Weaven, S. (2009). E-retailing by banks: e-service quality and its importance to customer satisfaction. European journal of marketing.

Dennis, C., Papagiannidis, S., Alamanos, E., \& Bourlakis, M. (2016). The role of brand attachment strength in higher education. Journal of Business Research, 69(8), 3049-3057.

Foroudi, P., Akarsu, T. N., Ageeva, E., Foroudi, M. M., Dennis, C., \& Melewar, T. C. (2018). PROMISING THE DREAM: Changing destination image of London through the effect of website place. Journal of Business Research, 83, 97-110. doi:10.1016/j.jbusres.2017.10.003

Fournier, S. (1998). Consumers and their brands: Developing relationship theory in consumer research. Journal of consumer research, 24(4), 343-373.

Goyal, P., \& Chanda, U. (2017). A Bayesian Network Model on the association between CSR, perceived service quality and customer loyalty in Indian Banking Industry. Sustainable Production and Consumption, 10, 50-65.

Hair, J. F., Hult, G. T. M., Ringle, C., \& Sarstedt, M. (2016). A primer on partial least squares structural equation modeling (PLS-SEM): Sage publications.

Henseler, J., Ringle, C. M., \& Sarstedt, M. (2015). A new criterion for assessing discriminant validity in variancebased structural equation modeling. Journal of the academy of marketing science, 43(1), 115-135. 
Jabnoun, N., \& Hassan Al-Tamimi, H. A. (2003). Measuring perceived service quality at UAE commercial banks. International Journal of Quality \& Reliability Management, 20(4), 458-472.

Lee, M. K., \& Turban, E. (2001). A trust model for consumer internet shopping. International Journal of electronic commerce, 6(1), 75-91.

Lewis, B. R., \& Soureli, M. (2006). The antecedents of consumer loyalty in retail banking. Journal of Consumer Behaviour: An International Research Review, 5(1), 15-31.

Manika, D., Gregory-Smith, D., \& Papagiannidis, S. (2018). The influence of prior knowledge structures on website attitudes and behavioral intentions. Computers in Human Behavior, 78, 44-58. doi:10.1016/j.chb.2017.09.024

Muhammad, L. (2019). Do service firm employee and customer relations matter for customer forgiveness in service recovery? Asia Pacific Journal of Marketing and Logistics.

Muhammad, L., \& Gul-E-Rana. (2020). Mediating role of customer forgiveness between perceived justice and satisfaction. Journal of Retailing and Consumer Services, 52, 101886.

Muhammad, L., Mahadi, B., \& Hussin, N. (2017). Influence of social capital on customer's relationship satisfaction in the Pakistani banking industry. Asia Pacific Journal of Marketing and Logistics.

Park, C. W., MacInnis, D. J., Priester, J., Eisingerich, A. B., \& Iacobucci, D. (2010). Brand attachment and brand attitude strength: Conceptual and empirical differentiation of two critical brand equity drivers. Journal of Marketing, 74(6), 1-17.

Park, C. W., MacInnis, D. J., \& Priester, J. R. (2006). Beyond attitudes: Attachment and consumer behavior. Seoul National Journal, 12(2), 3-36.

Phillips, D. M., \& Baumgartner, H. (2002). The role of consumption emotions in the satisfaction response. Journal of consumer psychology, 12(3), 243-252.

Rana, G., Azizah, N., Ali, M., Shah, A., \& Muhammad, L. (2018). Impact of E-service Quality on Brand Attachment and Willingness to Spend More. Sindh University Research Journal (Science Series), 50(3D), 214-215.

Riaz, A., Gregor, S., \& Lin, A. (2018). Biophilia and biophobia in website design: Improving internet information dissemination. Information \& Management, 55(2), 199-214. doi:10.1016/j.im.2017.05.006

Thach, E. C., \& Olsen, J. (2006). The role of service quality in influencing brand attachments at winery visitor centers. Journal of Quality Assurance in Hospitality \& Tourism, 7(3), 59-77.

Thomson, M., MacInnis, D. J., \& Park, C. W. (2005). The ties that bind: Measuring the strength of consumers' emotional attachments to brands. Journal of consumer psychology, 15(1), 77-91.

Van Riel, A. C., Liljander, V., \& Jurriens, P. (2001). Exploring consumer evaluations of e-services: a portal site. International Journal of service Industry management, 12(4), 359-377.

Wolfinbarger, M., \& Gilly, M. C. (2003). e'TailQ: dimensionalizing, measuring and predicting etail quality. Journal of Retailing, 79(3), 183-198. doi:10.1016/s0022-4359(03)00034-4

Wu, Y., Cai, Y., \& He, J. (2019). How brand concepts represented as human values promote evaluation. Asia Pacific Journal of Marketing and Logistics.

Zeithaml, V. A., Bitner, M. J., \& Gremler, D. D. (2006). Integrating customer focus across the firm. Services marketing, New York, Mc-Graw-Hill/Irwin. 